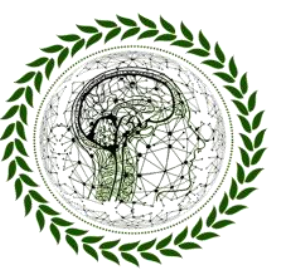

PhI Scientific Review

ISSN 2676 - 1444

Submetido em: 04/12/2021 | Aceito em: 07/12/2021 | Publicado em: 09/12/2021 | Artigo

\title{
ATUAÇÃO DO PSICÓLOGO EM CASOS DE ABUSO SEXUAL NA INFÂNCIA E ADOLESCÊNCIA: UMA REVISÃO DA LITERATURA
}

\author{
Adriana Farias dos Reis Ferreira, UNIFSA ${ }^{1}$ \\ Ana Caroline de C. F. Fernandes Macedo, UNIFSA ${ }^{2}$ \\ Audinéia da Silva de Castro, UNIFSA ${ }^{3}$ \\ Gil Marcos Pereira da Silva Júnior, UNIFSA ${ }^{4}$ \\ Luiz Marcus Silva do Nascimento, UNIFSA ${ }^{5}$ \\ Karoline Costa e Silva, UNIFSA ${ }^{6}$
}

\begin{abstract}
Resumo: Abuso sexual infanto-juvenil é considerado um dos tipos de violência grave, em que, atualmente, o número de ocorrências registradas vem aumentando consideravelmente, sem contar os casos não revelados, podendo ser influenciado devido a maioria deles, ocorrer em ambiente familiar. O presente artigo tem a finalidade de caracterizar as técnicas utilizadas pelos psicólogos em atendimentos de crianças e adolescentes que sofreram abuso sexual. A pesquisa foi do tipo revisão integrativa da literatura, considerando as bases de dados Scientific Electronic Library Online (Scielo), Literatura Latino-Americana e do Caribe em Ciências da Saúde (LILACS), Biblioteca Virtual em Saúde (BVS), Artigos, Teses entre outros, foram selecionados 9 artigos que atenderam aos critérios referentes ao objetivo. Os resultados da pesquisa indicam que são diversas as técnicas utilizadas pelos psicólogos em atendimentos de crianças e adolescentes que sofreram abuso sexual e percebeu-se uma predominância da Terapia Cognitiva Comportamental (TCC) nos estudos pesquisados, resultando na diminuição dos sintomas de ansiedade, depressão e estresse, bem como na percepção do abuso e na modificação de comportamentos disfuncionais.
\end{abstract}

Palavras-chave: Abuso sexual. Violência sexual. Terapia cognitivo comportamental. Infância e adoelscência.

\footnotetext{
1 Graduanda do curso de Psicologia do Centro Universitário Santo Agostinho - UNIFSA, e-mail: dricareis14@outlook.com, ORCID: 0000-0002-7701-9805

2 Graduanda do curso de Psicologia do Centro Universitário Santo Agostinho - UNIFSA, e-mail: anaccff@gmail.com

3 Graduanda do curso de Psicologia do Centro Universitário Santo Agostinho - UNIFSA, e-mail: audineia.castro@yahoo.com.br

4 Graduando do curso de Psicologia do Centro Universitário Santo Agostinho - UNIFSA, e-mail: gil0123marcos@gmail.com

5 Graduando do curso de Psicologia do Centro Universitário Santo Agostinho - UNIFSA, e-mail: vicenteluiz32229774@gmail.com

6 Psicóloga, Mestre em Psicologia Clínica, Professora do Curso de Psicologia do Centro Universitário Santo Agostinho, e-mail: psicologa.karoline@gmail.com
}

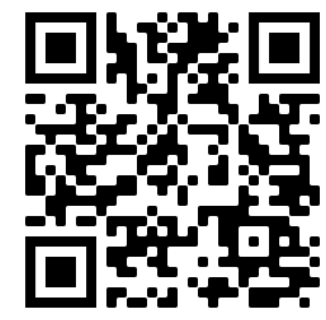

http://www.revistaphd.periodikos.com.br

V. 01, N $\mathrm{N}^{\mathrm{0}}$ 07, dezembro de 2021

DOI: 10.53497/phdsr1n7-001

Todos os direitos reservados $\odot$ 


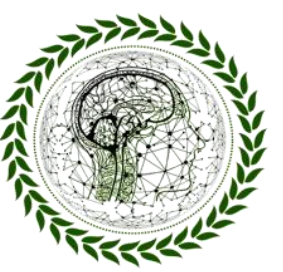

PhI Scientific Review

ISSN 2676 - 0444

\title{
ACTING OF THE PSYCHOLOGIST IN CASES OF SEXUAL ABUSE IN CHILDHOOD AND
} ADOLESCENCE: A LITERATURE REVIEW

\begin{abstract}
Child-juvenile sexual abuse is considered one of the types of serious violence, in which, currently, the number of registered occurrences has increased considerably, not counting the undisclosed cases, which can be influenced because most occur in the family environment. This article aims to characterize the techniques used by psychologists in assisting children and adolescents who have suffered sexual abuse. The research was an integrative literature review, considering the databases Scientific Electronic Library Online (Scielo), Latin American and Caribbean Literature on Health Sciences (LILACS), Virtual Health Library (VHL), Articles, Theses among others, 9 articles were selected that met the criteria related to the objective. The research results indicate that there are several techniques used by psychologists in the care of children and adolescents who have suffered sexual abuse and a predominance of Cognitive Behavior Therapy (CBT) in the researched studies was noticed, resulting in the reduction of symptoms of anxiety, depression and stress, as well as in the perception of abuse and in the modification of dysfunctional behaviors.
\end{abstract}

Keywords: Sexual abuse. Sexual violence. Cognitive behavioral therapy. Childhood and adolescence.

\section{INTRODUÇÃO}

O abuso sexual na infância e adolescência é um tema de grande relevância no contexto social em que suas marcas não são visíveis, mas suas consequências causam mudança de comportamento, podendo também desenvolver algum transtorno e durar até a vida adulta.

A partir de relatos sobre o assunto e estatísticas mundiais acerca da violência sexual envolvendo crianças e adolescentes, observou-se o quanto é necessário um estudo mais aprofundado sobre a importância do psicólogo especializado para acompanhar essas crianças e adolescentes abalados psicologicamente.

No cenário brasileiro, dados da Ouvidoria Nacional dos Direitos Humanos revela que, nos anos de 2015 e 2016, o disque 100 recebeu mais de 33 mil denúncias em relação à violência sexual perpetrada contra crianças e adolescentes (BRASIL, 2016). O boletim epidemiológico do Ministério da Saúde mostra que de 2011 a 2018 foram notificados 184.524 mil casos de violência sexual, dos quais $76,5 \%$ foram cometidos contra criança e adolescentes, situação que pode estar

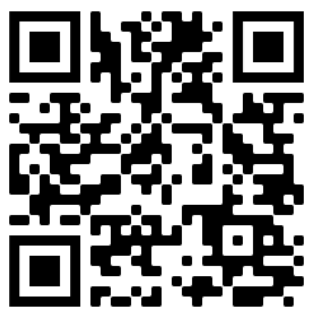

http://www.revistaphd.periodikos.com.br

V. 01, No 07, dezembro de 2021

DOI: $10.53497 /$ phdsr1n7-001

Todos os direitos reservados $(\mathrm{C}$ 


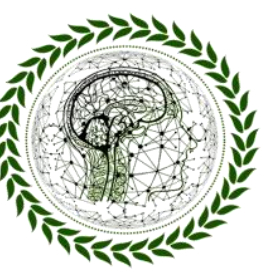

PhD Scientific Review

ISSN 2676 - 1444

relacionada à maior vulnerabilidade dessa faixa etária (BRASIL, 2018).

No Brasil, dados revelam que nos anos 2015 e 2016, 59\% das denúncias referentes à violência sexual tinham como principais suspeitos os genitores, com maior ocorrência no ambiente doméstico, sendo que 53\% correspondia ao lar da vítima e $26 \%$ a casa da(o) suspeita(o) (BRASIL, 2016; BRASIL, 2018). Outra pesquisa nacional, realizada a partir de 700 prontuários de vítimas de violência sexual em Teresina, Piauí, apontou que 46,7\% dos casos ocorreram no ambiente doméstico, sendo os pais e padrastos os principais agressores (SOARES et al., 2016). Esses dados que nos levam a acreditar, que com a medida de isolamento social durante a pandemia enfrentada pelo coronavírus a violência sexual infanto-juvenil assola diversos lares brasileiros.

Embora muito se fale atualmente sobre violência sexual, entender sobre o conceito pode auxiliar em um direcionamento ao combate do abuso sexual infanto-juvenil, pois é através dele que podemos determinar onde está o abuso, como ele pode ser classificado, e quem pode ser o abusador.

Define-se como abuso sexual qualquer contato ou interação entre uma criança ou adolescente e alguém em estágio psicossexual mais avançado do desenvolvimento, na qual a criança ou adolescente está sendo usado para estimulação sexual do perpetrador.

A interação sexual pode incluir toques, carícias, sexo oral ou relações com penetração (digital, genital ou anal). O abuso sexual também inclui situações nas quais não há contato físico, tais como voyerismo, assédio e exibicionismo. Estas interações sexuais são impostas às crianças ou aos adolescentes pela violência física, ameaças ou indução de sua vontade (HABIGZANG, 2008). É bem provável que uma criança e adolescente acometidos pelo abuso sexual apresente dificuldade no âmbito escolar, pela falta de concentração e atenção, podendo apresentar também bloqueios em relação com outras pessoas ocasionada pela desconfiança ou pelas alterações emocionais, mudando assim seu comportamento no convívio com outras crianças (HABIGZANG, 2008).

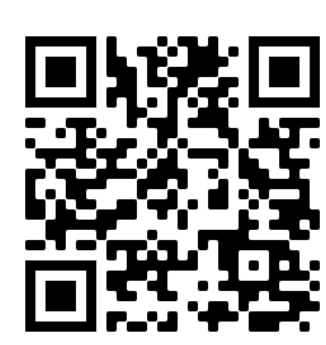

http://www.revistaphd.periodikos.com.br V. 01, No 07, dezembro de 2021 DOI: $10.53497 /$ phdsr1n7-001 Todos os direitos reservados ( 


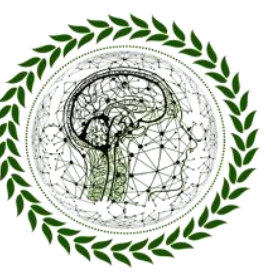

PhD Scientific Review

ISSN 2676 - 0444

Através desse conjunto de informações surge a questão de como o psicólogo tem intervindo nessa situação. Para um justo entendimento, Azevedo (2001) nos retrata um ponto de extrema importância, onde uma maneira eficaz de combate e prevenção ao abuso sexual é através de um maior preparo dos profissionais que atuam mais diretamente como seres humanos, não somente psicólogos, mas também pedagogos, médicos, fisioterapeutas, professores e outros mais.

Diante do exposto, o presente artigo tem como objetivo geral caracterizar as técnicas utilizadas pelos psicólogos em atendimentos de crianças e adolescentes que sofreram abuso sexual.

\section{MÉTODO}

Trata-se de uma revisão integrativa da literatura, cujo método consiste em uma síntese dos achados apresentados pelas pesquisas sobre um determinado tema ou questão, o que possibilita uma análise ampliada acerca da produção do saber sobre a temática, bem como a visualização de lacunas existentes (ERCOLE; MELO; ALCOFORADO, 2014). Esse aprofundamento do conhecimento, por sua vez, oferece subsídios passíveis de direcionar o desenvolvimento de ações de intervenção na atenção à saúde e a indicação de novos estudos.

O estudo respeitou os preceitos da Lei 9.610/1988, que versa sobre os direitos autorais dando o devido crédito aos autores das publicações (BRASIL, 1998).

Para a sua realização foi formulado o seguinte questionamento: "Quais as técnicas usadas pelos psicólogos em atendimentos de crianças e adolescentes vítimas do abuso sexual?” E, para responder tal questionamento foi utilizada as seguintes bases de dados: Biblioteca Virtual em Saúde Psicologia (BVS PSI) e SciELO, no período de março a junho de 2021, mediante os descritores: abuso sexual, violência sexual e terapia cognitivo comportamental, os quais foram escolhidos de acordo com os Descritores em Ciências da Saúde (DECS), combinados com operadores booleanos (and e or) que em seus títulos e/ou resumos contemplassem o objetivo do

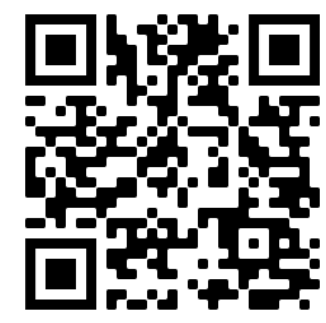

http://www.revistaphd.periodikos.com.br V. 01, No 07, dezembro de 2021 DOI: $10.53497 /$ phdsr1n7-001 Todos os direitos reservados@ 


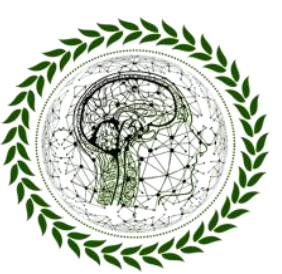

PhD Scientific Review

ISSN 2676 - 0444

presente estudo, excluindo-se aqueles que contemplassem população diversa da infanto- juvenil.

O estudo desenvolveu-se em cinco etapas, quais sejam: delimitação do tema e escolha da questão de pesquisa; determinação dos critérios de inclusão e exclusão dos estudos; identificação dos estudos pré-selecionados e os selecionados; classificação dos estudos escolhidos; e a análise e interpretação dos resultados. Após a verificação das publicações, os resumos foram analisados, adequando-os de acordo com os critérios de inclusão/exclusão preestabelecidos, que serão descritos na sequência.

Foram incluídos neste estudo todos os artigos empíricos encontrados, no idioma português, em revistas indexadas, teses e dissertações, com os descritores que respondessem ao problema de pesquisa, sendo selecionados nove artigos científicos com diferentes métodos de estudo. Deixou-se de incluir, livros, capítulos de livros, resenhas, críticas, comentários, editoriais, anais e relatórios científicos. Ao todo, foram lidos 50 artigos, destes, 9 foram utilizados nesta pesquisa.

\section{RESULTADOS}

Foram incluídos nesta análise 9 estudos que versam sobre as repercussões do abuso sexual experienciado na infância e adolescência (Quadro 1).

Com relação ao ano de publicação dos artigos empíricos selecionados, compreendem o período de 2015 a 2021, sendo $2015(\mathrm{n}=1), 2016(\mathrm{n}=2), 2017(\mathrm{n}=1), 2018(\mathrm{n}=1), 2019$ ( $\mathrm{n}=2)$, $2020(n=1)$ e $2021(n=1)$.

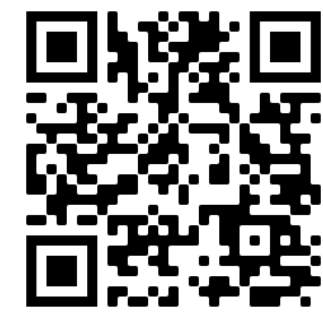

http://www.revistaphd.periodikos.com.br V. 01, No 07, dezembro de 2021 DOI: $10.53497 /$ phdsr1n7-001 Todos os direitos reservados $(\mathrm{C}$ 
PhI Scientific Review

ISSN 2676 - 0444

QUADRO 1: Quadro sinóptico com os dados principais dos estudos.

\begin{tabular}{|c|c|c|c|c|c|c|c|}
\hline $\mathbf{N}^{\circ}$ & TÍtULO & ANO & $\begin{array}{c}\text { OBJETIVO } \\
\text { ESTUDO }\end{array}$ & MÉTODO & $\begin{array}{c}\text { TÉCNICAS DE } \\
\text { TRATAMENTO }\end{array}$ & $\begin{array}{c}\text { RESULTADOS } \\
\text { CONSIDERAÇÕES } \\
\text { FINAIS }\end{array}$ & $\begin{array}{c}\text { PRINCSULTADAIS } \\
\text { APRECIAÇÕES } \\
\text { DO GRUPO }\end{array}$ \\
\hline
\end{tabular}

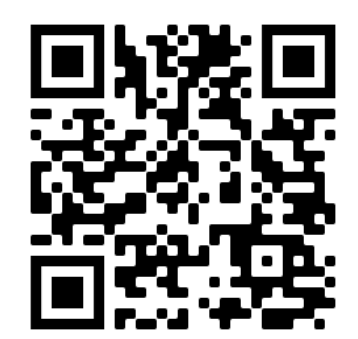

http://www.revistaphd.periodikos.com.br

V. 01, No 07, dezembro de 2021 DOI: 10.53497/phdsr1n7-001

Todos os direitos reservados(C) 


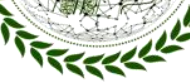

PhI Scientific Review

ISSN 2676 - 0444

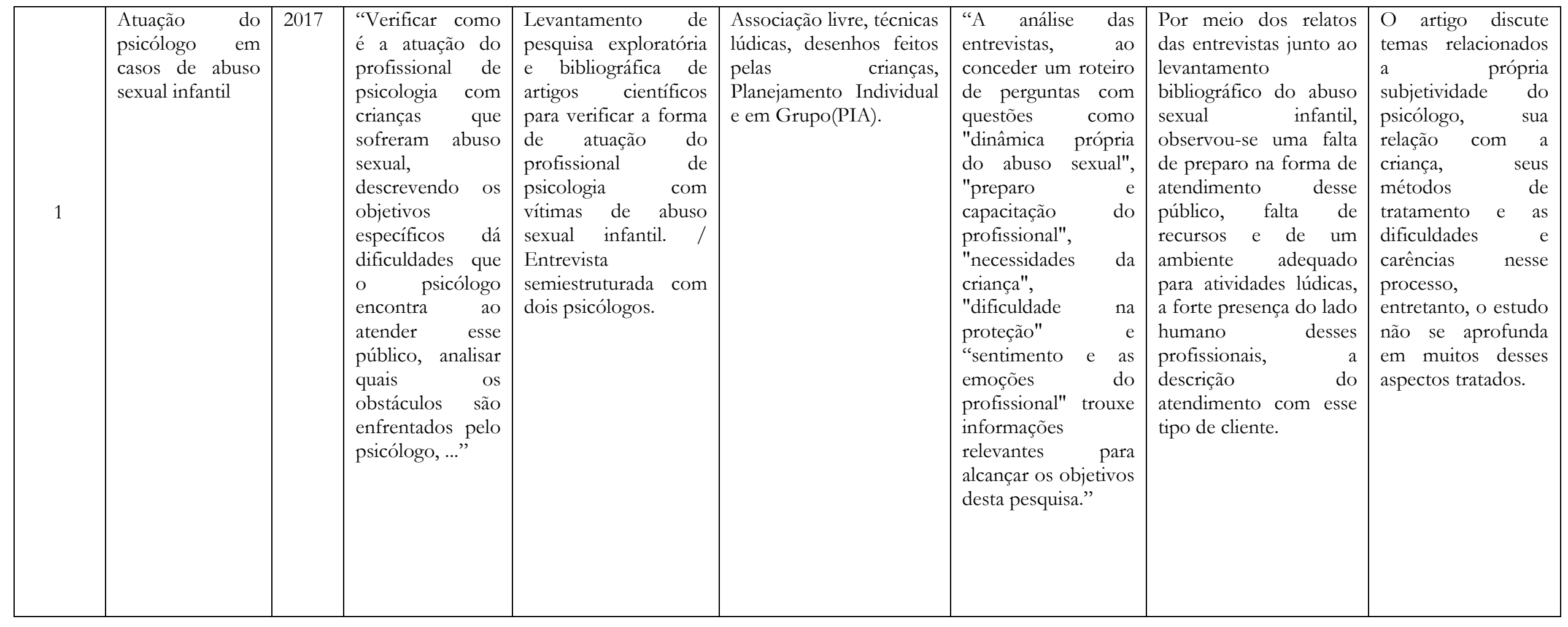

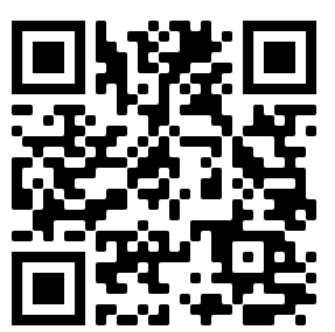

http://www.revistaphd.periodikos.com.br

V. 01, No 07, dezembro de 2021

DOI: $10.53497 /$ phdsr1n7-001

Todos os direitos reservados $($ ) 
PhID Scientific Review

ISSN 2676 - 0444

\begin{tabular}{|c|c|c|c|c|c|c|c|c|}
\hline 2 & $\begin{array}{lr}\text { Intervenções da } \\
\text { Terapia } \\
\text { Cognitivo- } \\
\text { Comportamental } \\
\text { (TCC) para } \\
\text { transtorno de } \\
\text { estresse pós- } \\
\text { traumático: } \\
\text { estudo de caso }\end{array}$ & 2021 & 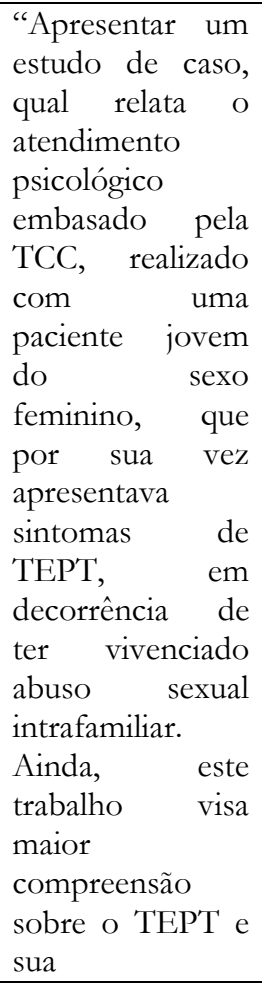 & $\begin{array}{l}\text { "Pesquisa qualitativa } \\
\text { de cunho exploratório } \\
\text { e descritivo, cuja } \\
\text { análise foi baseada em } \\
\text { teorias. Utilizou-se de } \\
\text { estudo de caso único } \\
\text { para o } \\
\text { desenvolvimento } \\
\text { visto que este busca a } \\
\text { investigação de uma } \\
\text { realidade, a fim de } \\
\text { compreensão total e } \\
\text { transformação no } \\
\text { conteúdo obtido em } \\
\text { escrita científica." }\end{array}$ & $\begin{array}{l}\text { Instrumentos de } \\
\text { Avaliação: Inventário de } \\
\text { Depressão de } \\
\text { Beck(BECK; STEER; } \\
\text { BROWN, 2011), Escala } \\
\text { Wechsler de Avaliação } \\
\text { Breve de Inteligência } \\
\text { (WECHSLER, } \\
\text { 2014);Instrumentos } \\
\text { Terapêuticos: } \\
\text { Psicoeducação, } \\
\text { desenhos, reestruturação } \\
\text { cognitiva }\end{array}$ & $\begin{array}{l}\text { "Constatou-se } \\
\text { efetividade ao longo } \\
\text { do tratamento, } \\
\text { considerando a } \\
\text { sintomatologia } \\
\text { inicial e final, bem } \\
\text { por observações } \\
\text { clínicas e avalições } \\
\text { de testes } \\
\text { psicológicos. } \\
\text { Utilizam-se técnicas } \\
\text { da TCC, como a } \\
\text { reestruturação } \\
\text { cognitiva, exposição } \\
\text { prolongada } \\
\text { trauma e técnicas de } \\
\text { relaxamento, para } \\
\text { promoção do bem- - } \\
\text { estar e manejo de } \\
\text { sintomas que } \\
\text { causassem prejuízo } \\
\text { funcional. Entende- } \\
\text { se que apesar de ser } \\
\text { evidenciado } \\
\text { progressos nos no no }\end{array}$ & $\begin{array}{l}\text { "A vivência de uma } \\
\text { experiência traumática } \\
\text { pode acarretar efeitos } \\
\text { no desenvolvimento do } \\
\text { sujeito, afetando-o em } \\
\text { tarefas cotidianas, } \\
\text { dificultando no } \\
\text { estabelecimento de } \\
\text { relações afetivas e } \\
\text { sociais, assim como em } \\
\text { seu funcionamento. O } \\
\text { TEPT causa sofrimento } \\
\text { psíquico, a partir do } \\
\text { qual há necessidade de } \\
\text { amparar, } \\
\text { psicologicamente, o } \\
\text { sujeito e fornecer-lhe } \\
\text { instrumentos para que } \\
\text { entenda os } \\
\text { acontecimentos que } \\
\text { vivenciou." }\end{array}$ & 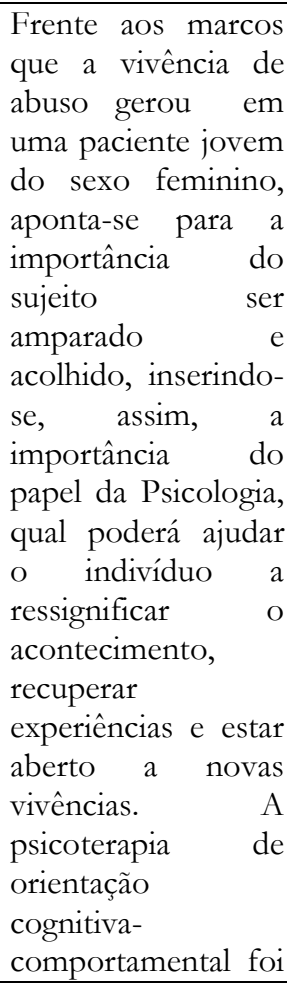 \\
\hline
\end{tabular}

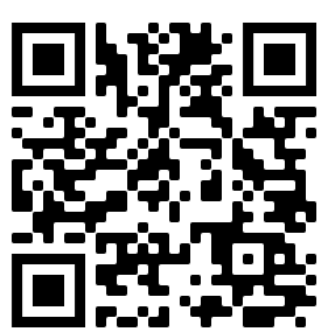

http://www.revistaphd.periodikos.com.br

V. 01, No 07, dezembro de 2021

DOI: $10.53497 /$ phdsr1n7-001

Todos os direitos reservados@ 


\section{PhI Scientific Review}

ISSN 2676 - 0444

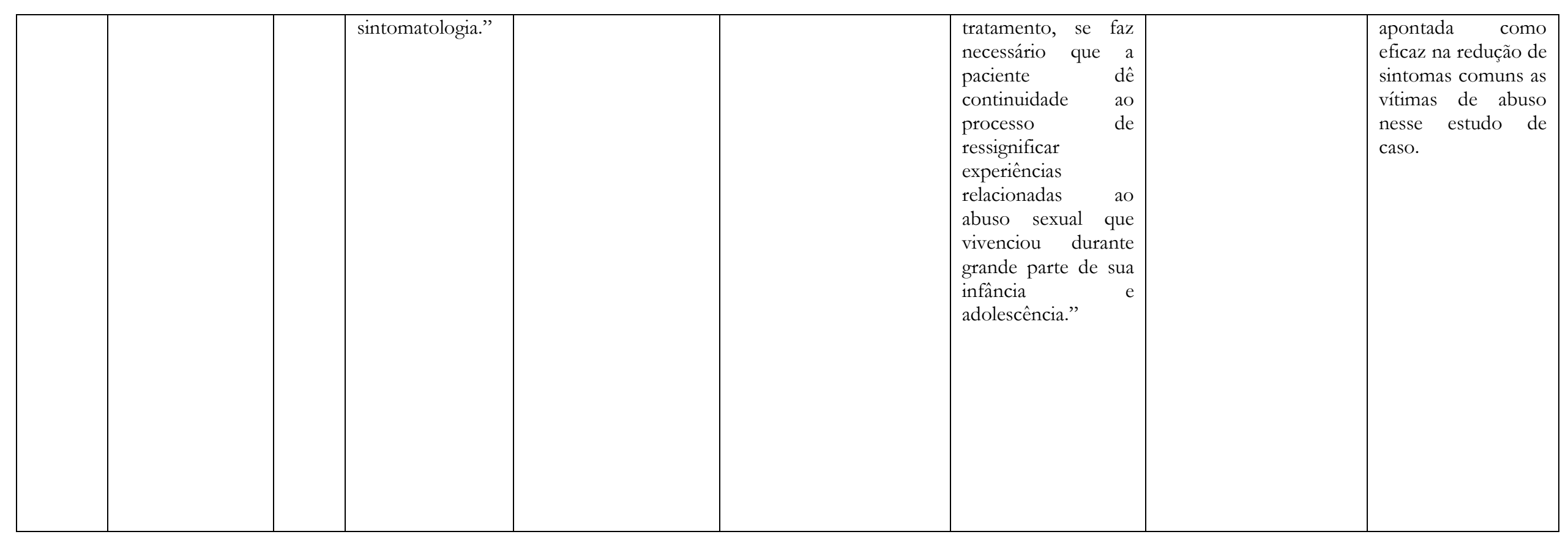

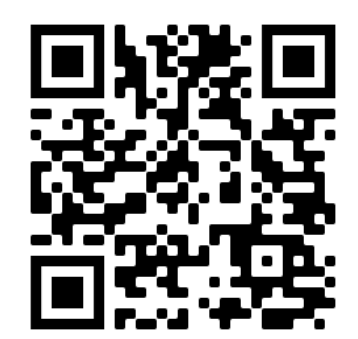

http://www.revistaphd.periodikos.com.br

V. 01, No 07, dezembro de 2021 DOI: 10.53497/phdsr1n7-001

Todos os direitos reservados@ 


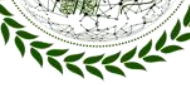

PhI Scientific Review

ISSN 2676 - 0444

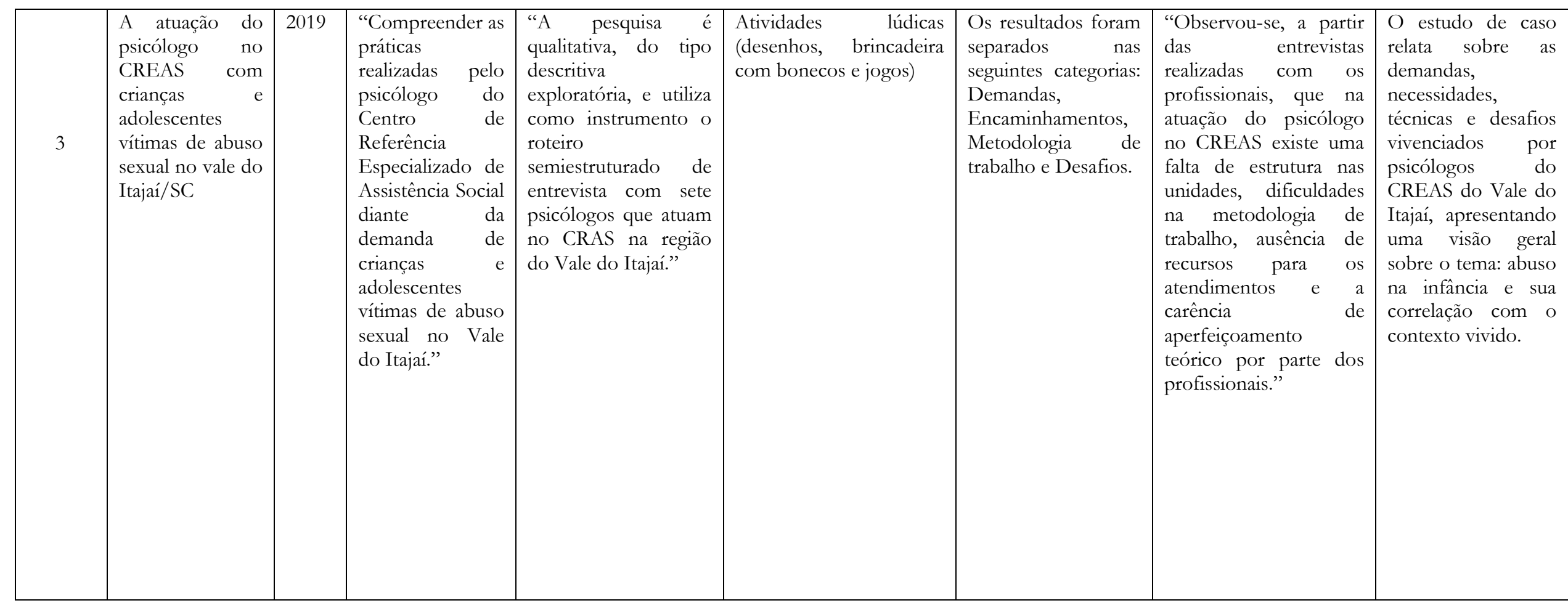

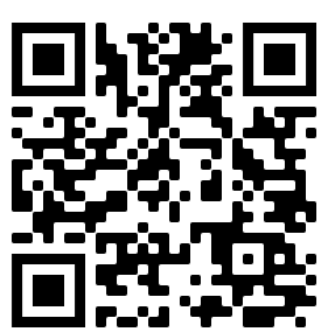

http://www.revistaphd.periodikos.com.br

V. 01, No 07, dezembro de 2021 DOI: $10.53497 /$ phdsr1n7-001

Todos os direitos reservados $($ ) 
PhID Scientific Review

ISSN 2676 - 0444

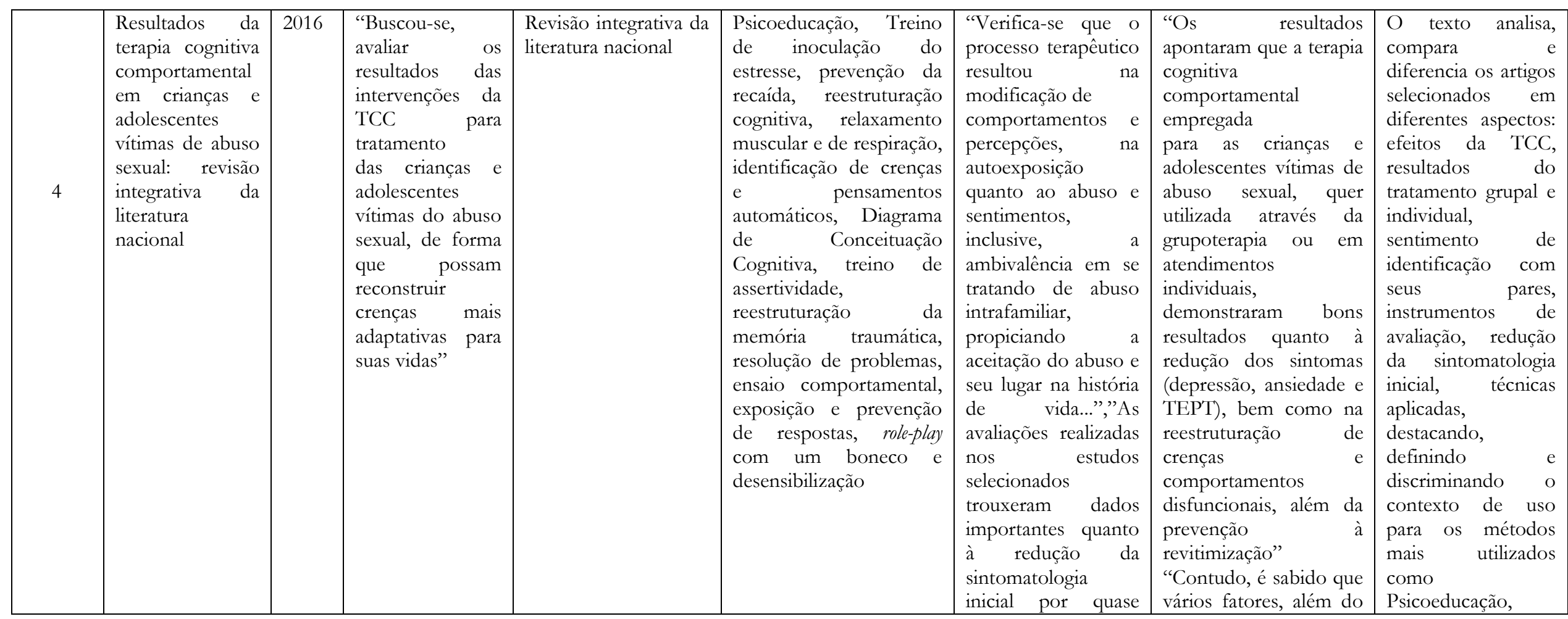

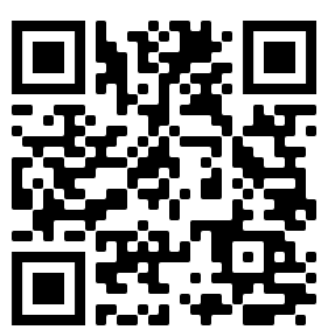

http://www.revistaphd.periodikos.com.br

V. 01, No 07, dezembro de 2021

DOI: $10.53497 /$ phdsr1n7-001

Todos os direitos reservados@ 
PhID Scientific Review

ISSN 2676 - 0444

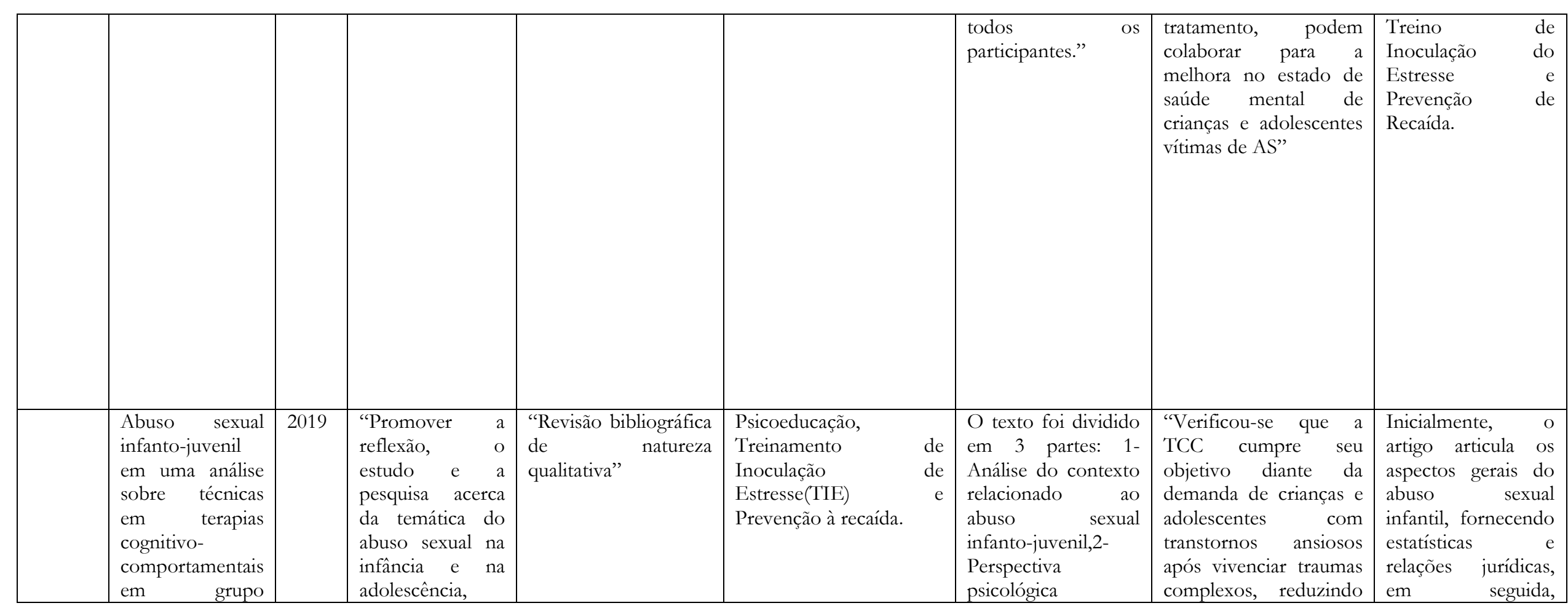

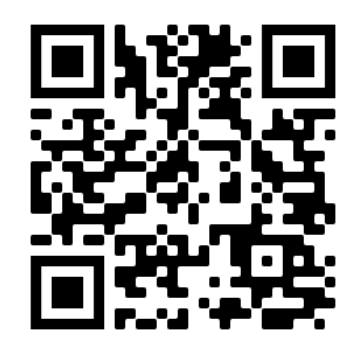

http://www.revistaphd.periodikos.com.br

V. 01, No 07, dezembro de 2021 DOI: $10.53497 /$ phdsr1n7-001

Todos os direitos reservados@ 
PhI Scientific Review

ISSN 2676 - 0444

\begin{tabular}{|c|c|c|c|c|c|c|c|c|}
\hline 5 & (TCCG) & & $\begin{array}{l}\text { tendo como luz a } \\
\text { terapia cognitiva- } \\
\text { comportamental" }\end{array}$ & & & \begin{tabular}{l}
\multicolumn{3}{l}{ interconectando-a } \\
com a TCC,3- \\
Análise das técnicas \\
mais utilizadas e \\
suas eficácias \\
(Psicoeducação, \\
Treinamento de \\
Inoculação de \\
Estresse, Prevenção \\
de Recaída)
\end{tabular} & $\begin{array}{lr}\text { sintomas e } & \text { sendo } \\
\text { corresponsável } & \text { pela } \\
\text { diminuição } & \text { de } \\
\text { recidivas." ... "A terapia } \\
\text { cognitiva- } \\
\text { comportamental } \\
\text { mediante uso } \\
\text { técnicas } \\
\text { psicoeducação, } \\
\text { treinamento das } \\
\text { inoculação de estresse e } \\
\text { prevenção à recaída, } \\
\text { mostrou de } \\
\text { resultados nos pacientes } \\
\text { que no início do } \\
\text { tratamento } \\
\text { apresentaram } \\
\text { índice de ansiedade, } \\
\text { medo e culpa" }\end{array}$ & $\begin{array}{l}\text { correlaciona os AS } \\
\text { infantil ao âmbito } \\
\text { psicológico, em } \\
\text { particular a terapia } \\
\text { cognitivo } \\
\text { comportamental e } \\
\text { suas capacidades de } \\
\text { mudança cognitiva, } \\
\text { para em seguida, } \\
\text { detalhar as } \\
\text { principais técnicas } \\
\text { cognitivos- } \\
\text { comportamentais, } \\
\text { considerando suas } \\
\text { características, } \\
\text { possíveis resultados } \\
\text { produzidos e } \\
\text { possibilidades de } \\
\text { atuação em grupo. }\end{array}$ \\
\hline & $\begin{array}{l}\text { Terapia } \\
\text { Cognitivo- } \\
\text { Comportamental } \\
\text { em situação de } \\
\text { Abuso Sexual: }\end{array}$ & 2018 & $\begin{array}{l}\text { "Descrever uma } \\
\text { intervenção } \\
\text { realizada por } \\
\text { meio da Terapia } \\
\text { Cognitivo- }\end{array}$ & $\begin{array}{l}\text { Pesquisa qualitativa } \\
\text { de cunho exploratório }\end{array}$ & $\begin{array}{ll}\text { Instrumentos } & \text { de } \\
\text { Avaliação: Registro de } \\
\text { Pensamentos } \\
\text { Disfuncionais(RPD), } \\
\text { Exame de Evidências, }\end{array}$ & $\begin{array}{lr}\text { Ademais, a } & \text { paciente } \\
\text { aderiu de } & \text { maneira } \\
\text { significativa } & \text { ao } \\
\text { tratamento } & \text { obtendo } \\
\text { respostas } & \end{array}$ & $\begin{array}{l}\text { Haja vista a severidade } \\
\text { do tema, necessita-se } \\
\text { que o conhecimento } \\
\text { psicológico e r suas } \\
\text { práticas }\end{array}$ & $\begin{array}{l}\text { O texto analisa um } \\
\text { caso particular de } \\
\text { abuso sexual } \\
\text { infanto-juvenil, } \\
\text { descrevendo o }\end{array}$ \\
\hline
\end{tabular}

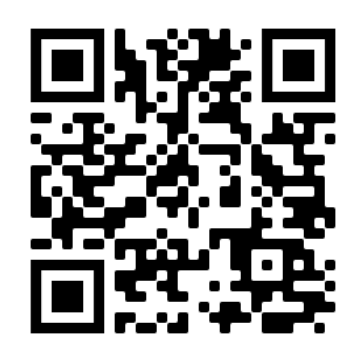

http://www.revistaphd.periodikos.com.br

V. 01, No 07, dezembro de 2021

DOI: $10.53497 /$ phdsr1n7-001

Todos os direitos reservados@ 
PhI Scientific Review

ISSN 2676 - 0444

\begin{tabular}{|c|c|c|c|c|c|c|c|c|}
\hline 6 & $\begin{array}{l}\text { um Estudo de } \\
\text { Caso }\end{array}$ & & $\begin{array}{l}\text { Comportamental } \\
\text { para redução do } \\
\text { medo, culpa e } \\
\text { ansiedade } \\
\text { antecipatória em } \\
\text { uma paciente que } \\
\text { sofreu abuso } \\
\text { sexual." }\end{array}$ & & $\begin{array}{l}\text { Inventário de Ansiedade; } \\
\text { Instrumentos } \\
\text { Terapêuticos: } \\
\text { Psicoeducação, } \\
\text { Respiração } \\
\text { Diafragmática } \\
\text { (Knapp,2004), } \\
\text { Torta } \\
\text { Responsabilidade para } \\
\text { Culpa ou Vergonha } \\
\text { (Greenberger \& Pa- } \\
\text { desky, } 2017 \text { ), } \\
\text { Descatastrofização, } \\
\text { Prevenção à Recaída. }\end{array}$ & 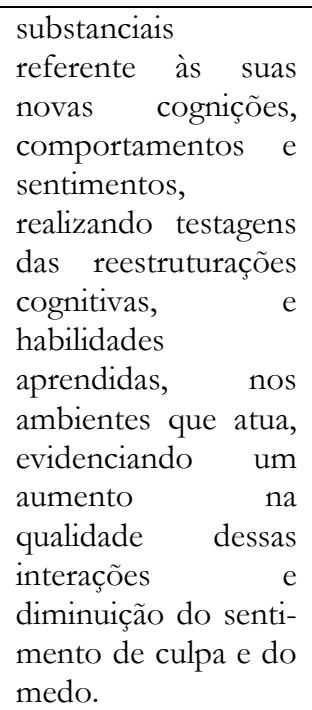 & $\begin{array}{l}\text { solidamente respaldadas } \\
\text { em dados empíricos, } \\
\text { para que assim, novos } \\
\text { recursos e intervenções } \\
\text { sejam elaboradas } \\
\text { visando possibilitar o } \\
\text { progresso científico nos } \\
\text { estudos relativos à área. }\end{array}$ & 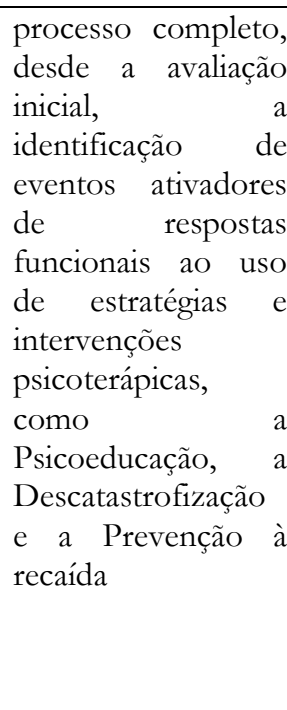 \\
\hline & $\begin{array}{lr}\text { Atuação } & \text { de } \\
\text { Psicólogos em } & \text { Alegações de } \\
\text { Violência Sexual: } \\
\text { Boas Práticas nas } \\
\text { Entrevistas de }\end{array}$ & 2020 & $\begin{array}{lr}\text { "Discutir } & \text { a } \\
\text { escuta } & \text { do } \\
\text { psicólogo/a } & \\
\text { sobre } & \text { alegações } \\
\text { de } & \text { violência } \\
\text { sexual } & \text { nos } \\
\text { contextos } & \text { da }\end{array}$ & $\begin{array}{l}\text { Revisão bibliográfica } \\
\text { de literatura }\end{array}$ & $\begin{array}{l}\text { Escuta } \\
\text { Especializada(EF), } \\
\text { Depoimento } \\
\text { Especial(DE), Perícia } \\
\text { Psicológica e rapport. }\end{array}$ & $\begin{array}{l}\text { "Observou-se que a } \\
\text { escuta especializada } \\
\text { aindar requer } \\
\text { diretrizes mais } \\
\text { específicas para seus } \\
\text { procedimentos, bem } \\
\text { como a adoção de }\end{array}$ & $\begin{array}{lrr}\text { "Observou-se } & \text { a } \\
\text { necessidade } & \text { de } \\
\text { qualificação } & & \text { dos } \\
\text { psicólogos para a } & \text { atuação } & \text { nessas } \\
\text { entrevistas, bem } & \text { como } \\
\text { a necessidade } & \text { da }\end{array}$ & $\begin{array}{lr}\text { Através de uma } \\
\text { revisão da literatura } \\
\text { o artigo procurou } \\
\text { caracterizar } \\
\text { contexto } & \mathrm{d} \\
\text { trabalho e } & \text { como }\end{array}$ \\
\hline
\end{tabular}

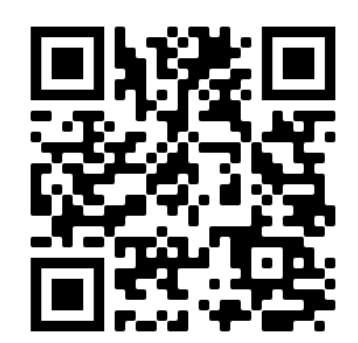

http://www.revistaphd.periodikos.com.br

V. 01, No 07, dezembro de 2021

DOI: $10.53497 /$ phdsr1n7-001

Todos os direitos reservados ( 


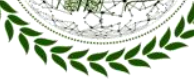

PhI Scientific Review

ISSN 2676 - 144

\begin{tabular}{|c|c|c|c|c|c|c|c|c|}
\hline 7 & $\begin{array}{ll}\text { Crianças } & \mathrm{e} \\
\text { Adolescentes } & \end{array}$ & & $\begin{array}{l}\text { escuta } \\
\text { especializada, do } \\
\text { depoimento } \\
\text { especial e da } \\
\text { perícia } \\
\text { psicológica e } \\
\text { apresentar } \\
\text { diretrizes gerais } \\
\text { para entrevistas } \\
\text { com crianças e } \\
\text { adolescentes, } \\
\text { consideradas na } \\
\text { literatura como } \\
\text { boas práticas } \\
\text { nesse campo de } \\
\text { atuação." }\end{array}$ & & & 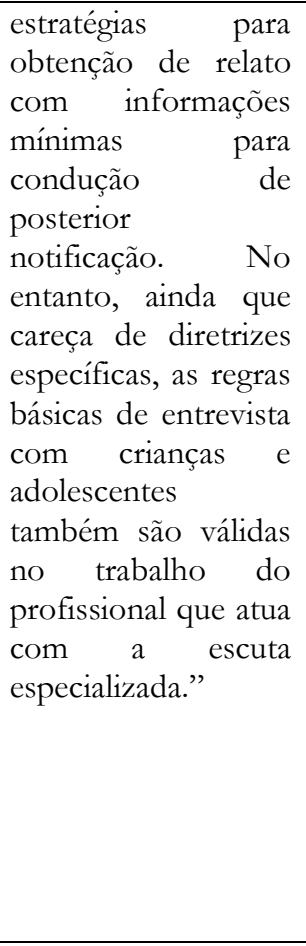 & $\begin{array}{l}\text { realização de } \text { estudos } \\
\text { nesses diferentes } \\
\text { contextos de trabalho e } \\
\text { procedimentos." }\end{array}$ & $\begin{array}{l}\text { esses três } \\
\text { procedimentos são } \\
\text { realizados no } \\
\text { sistema de garantia } \\
\text { de direitos: Escuta } \\
\text { especializada, } \\
\text { depoimento especial } \\
\text { e perícia } \\
\text { psicológica. A partir } \\
\text { da literatura } \\
\text { internacional, } \\
\text { buscou-se trazer os } \\
\text { parâmetros } \\
\text { esperados para } \\
\text { condução das } \\
\text { entrevistas forenses, } \\
\text { que constituem as } \\
\text { diretrizes das boas } \\
\text { práticas que já há } \\
\text { anos vem sendo } \\
\text { estudadas por } \\
\text { pesquisadores em } \\
\text { diferentes partes do } \\
\text { mundo. }\end{array}$ \\
\hline & Práticas & 2015 & "Verificar como & Delineamento: "Foi & Entrevista & Os resultados foram & $\mathrm{O}$ artigo discute, o uso & \\
\hline
\end{tabular}

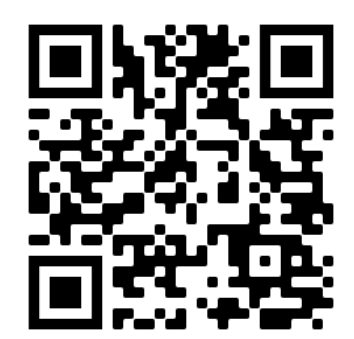

http://www.revistaphd.periodikos.com.br

V. 01, No 07, dezembro de 2021 DOI: $10.53497 /$ phdsr1n7-001

Todos os direitos reservados@ 


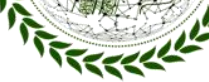

PhI Scientific Review

ISSN 2676 - 0444

\begin{tabular}{|c|c|c|c|c|c|c|c|}
\hline 8 & $\begin{array}{lr}\text { profissionais } & \text { de } \\
\text { Psicologia } & \text { em } \\
\text { situações } & \text { de } \\
\text { abuso sexual } & \end{array}$ & $\begin{array}{lr}\text { Os psicólogos } \\
\text { brasileiros } & \text { estão } \\
\text { atuando nessas } & \text { nituações, } \\
\text { incluindo } & \text { sua } \\
\text { qualificação } & \text { e } \\
\text { experiência, } & \\
\text { familiaridade } & \\
\text { com a literatura, } \\
\text { percepções e e } \\
\text { práticas } \\
\text { profissionais." }\end{array}$ & 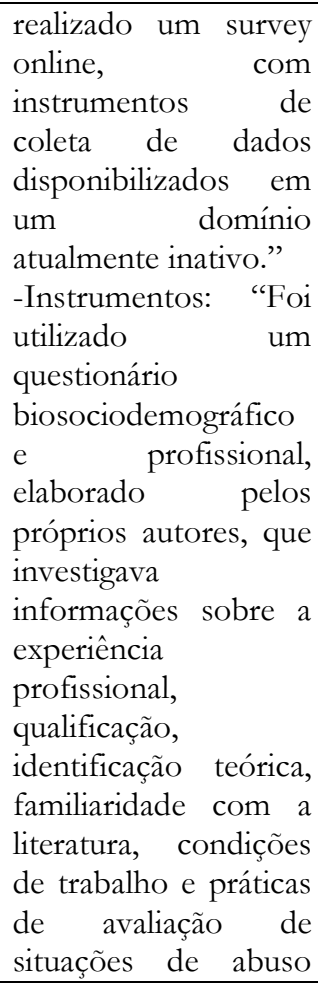 & $\begin{array}{l}\text { cuidadores não abusivos, } \\
\text { Entrevista com o } \\
\text { suposto abusador, } \\
\text { Entrevista com a criança, } \\
\text { Entrevista cognitiva, } \\
\text { Avaliação da Validade da } \\
\text { Declaração - Statement } \\
\text { Validity Assessment - } \\
\text { SVA, Família } \\
\text { terapêutica, } \\
\text { Bonecos anatômicos, } \\
\text { Instrumentos } \\
\text { psicométricos, com } \\
\text { Instrumentos projetivos, } \\
\text { Entrevistas profissionais, Hora do } \\
\text { jogo/Entrevista lúdica. }\end{array}$ & $\begin{array}{l}\text { separados entre } \\
\text { Qualificação } \\
\text { experiência } \\
\text { profissional, } \\
\text { Identificação } \\
\text { Teórica (a pesquisa } \\
\text { mostrou um maior } \\
\text { destaque para Teoria } \\
\text { Psicanalítica), } \\
\text { Familiaridade com a } \\
\text { literatura específica, } \\
\text { Práticas } \\
\text { profissionais } \\
\text { (Destacou } \\
\text { frequência de uso } \\
\text { dos instrumentos e } \\
\text { procedimentos, a de } \\
\text { maior frequência de } \\
\text { uso é a entrevista } \\
\text { com a criança) }\end{array}$ & $\begin{array}{l}\text { da psicanálise, a atuação } \\
\text { do psicólogo no meio } \\
\text { jurídico, como um } \\
\text { avaliador, contudo, com } \\
\text { relação às práticas } \\
\text { psicológicas e ao uso de } \\
\text { instrumentos “... os } \\
\text { profissionais indicaram } \\
\text { permanecer utilizando } \\
\text { muito mais técnicas } \\
\text { tradicionais do que } \\
\text { novas ferramentas. .... } \\
\text { O que fica evidente é a } \\
\text { centralidade da } \\
\text { entrevista como meio } \\
\text { de coleta de dados e } \\
\text { como meio principal de } \\
\text { avaliação das situações } \\
\text { de abuso sexual." }\end{array}$ & $\begin{array}{l}\text { O artigo realiza uma } \\
\text { pesquisa online e se } \\
\text { desenvolve a partir } \\
\text { da análise desses } \\
\text { dados, ainda que } \\
\text { não se aprofunde } \\
\text { em todas as } \\
\text { informações } \\
\text { obtidas, destacando } \\
\text { os métodos } \\
\text { utilizados r pelos } \\
\text { psicólogos, sua } \\
\text { relação com o } \\
\text { Poder Judiciário e } \\
\text { importância da } \\
\text { psicanálise. }\end{array}$ \\
\hline
\end{tabular}

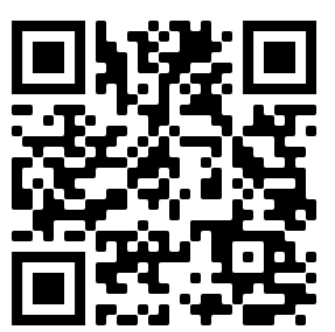

http://www.revistaphd.periodikos.com.br

V. 01, No 07, dezembro de 2021

DOI: $10.53497 /$ phdsr1n7-001

Todos os direitos reservados@ 


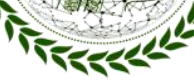

PhI Scientific Review

ISSN 2676 - 0444

\begin{tabular}{|c|c|c|c|c|c|c|c|c|}
\hline & & & & sexual." & & & & \\
\hline 9 & $\begin{array}{l}\text { Aplicação do } \\
\text { Programa } \\
\text { Cognitivo- } \\
\text { Comportamental } \\
\text { Superar para } \\
\text { atendimento } \\
\text { individual de } \\
\text { meninas vítimas } \\
\text { de violência } \\
\text { sexual: estudos } \\
\text { de caso }\end{array}$ & 2016 & 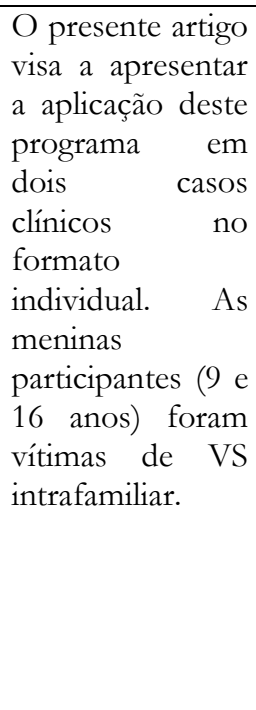 & $\begin{array}{l}\text { Trata-se de estudos } \\
\text { de casos clínicos, com } \\
\text { avaliação antes (pré- } \\
\text { teste) e depois (pós- } \\
\text { teste) da intervenção. }\end{array}$ & $\begin{array}{l}\text { Instrumentos } \\
\text { Avaliação: } \\
\text { semi-estruturada, Entrevista } \\
\text { de Estresse Infantil } \\
\text { (ESI), Inventário de } \\
\text { Depressão Infantil } \\
\text { (CDI), } \\
\text { estruturada com base no } \\
\text { DSM IV/ SCID para } \\
\text { avaliação de transtorno } \\
\text { do estresse pós- } \\
\text { traumático; } \\
\text { Instrumentos } \\
\text { Terapêuticos: } \\
\text { Psicoeducação(recursos } \\
\text { lúdicos, role-play, } \\
\text { relaxamento muscular e } \\
\text { respiração controlada), }\end{array}$ & 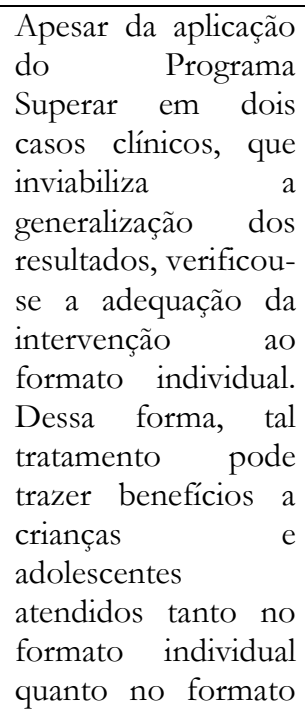 & $\begin{array}{l}\text { Verificou-se que o } \\
\text { Programa Superar teve } \\
\text { resultados positivos } \\
\text { também no formato } \\
\text { individual. O trabalho } \\
\text { da psicologia no } \\
\text { contexto clínico é parte } \\
\text { do trabalho que deve } \\
\text { ser desenvolvido por } \\
\text { uma rede complexa de } \\
\text { instituições que visam à } \\
\text { proteção, promoção de } \\
\text { saúde e garantia de } \\
\text { direitos de crianças e } \\
\text { adolescentes vítimas de } \\
\text { violência sexual. }\end{array}$ & 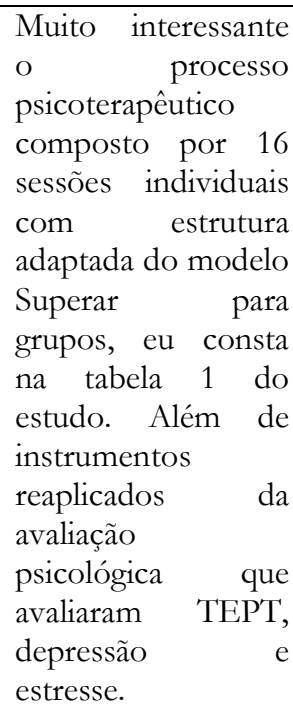 \\
\hline
\end{tabular}

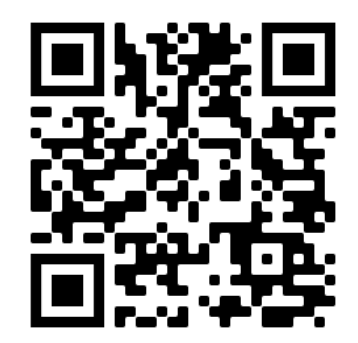

http://www.revistaphd.periodikos.com.br

V. 01, No 07, dezembro de 2021

DOI: $10.53497 /$ phdsr1n7-001

Todos os direitos reservados@ 
PhI Scientific Review

ISSN 2676 - 0444

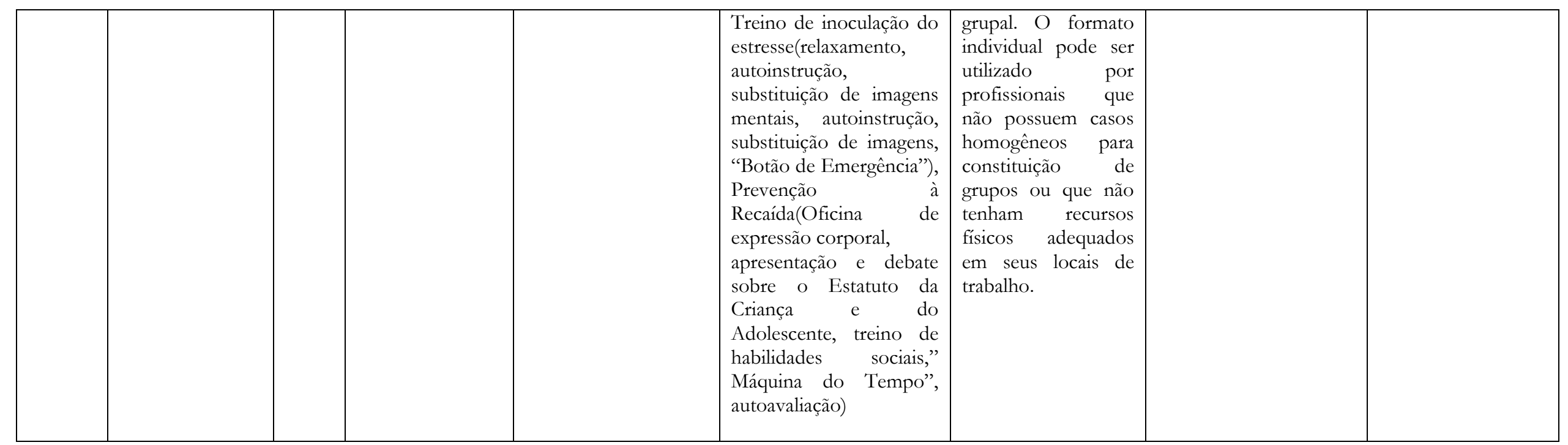

FONTE: Elaborado pelos autores com dados da BVS e SciELO (2021).

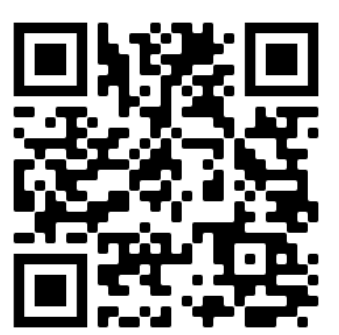

http://www.revistaphd.periodikos.com.br

V. 01, No 07, dezembro de 2021 DOI: 10.53497/phdsr1n7-001

Todos os direitos reservados@ 


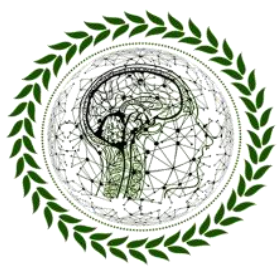

PhD Scientific Review

ISSN 2676 - 0444

\section{DISCUSSÃO}

Em estudos realizados nos artigos mencionados na tabela, foram levantados diversos questionamentos referentes a temática complexa sobre o abuso sexual na infância e adolescência, onde foi frisado a importância do papel do psicólogo e sua ajuda imprescindível, pois o psicoterapeuta especializado na área tem a capacidade para apurar detalhes da situação e saber lidar sem causar maiores danos psicológicos.

No artigo 1 podemos citar que abuso sexual é um problema relacionado à saúde pública, e pode se manifestar de duas maneiras: abuso intrafamiliar e extrafamiliar. O tempo de duração de cada um dependerá da forma, ou seja, o abuso intrafamiliar é praticado por um familiar ou alguém próximo, com tendência a ter uma maior durabilidade devido à criança se sentir intimidada e por medo das ameaças feitas pelo abusador, e em alguns casos por medo de ser considerada culpada pelo ato (AUGUSTO et al., 2017).

Um dos maiores problemas é de como essas crianças e adolescentes estão sendo acompanhadas após o ciclo de violência sexual em casa. O convívio com a família diante desta situação em questão deve ser levada a discussão de como encontrar meios para evitar o abuso e assim promover mudanças nessa realidade.

Podemos citar uma abordagem que pode auxiliar no tratamento do problema em questão. A terapia cognitiva-comportamental citada nos artigos: 2, 4, 5, 6 e 9 tem apresentado melhores resultados quando comparada com outras formas de tratamento não-focais para crianças e adolescentes com sintomas de ansiedade, depressão e problemas comportamentais decorrentes de violência sexual (COHEN; MANNARINO; KNUDSEN, 2005; DEBLINGER; STAUFFER; STEER, 2001; SAYWITZ; COLS., 2000, apud HABIGZANG, 2008).

O artigo 2 cita técnicas de Terapia Cognitivo-Comportamental (TCC) para propor relaxamento e uma reestruturação cognitiva, pois apesar de ter sido constatado progresso no tratamento é necessário uma continuação de ressignificação e construção. A vivência se torna umas das etapas mais traumáticas, pois afeta em todos os segmentos da vida da criança e do 


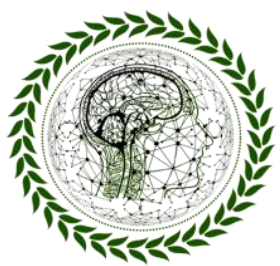

PhD Scientific Review

ISSN 2676 - 0444

adolescente, dificultando relações sociais e afetivas (MAFFINI, CASSEL, 2021).

Outro artigo em ênfase titulado "Adaptação e avaliação de uma intervenção cognitivocomportamental para meninos vítimas de violência sexual" tem como objetivo adaptar, aplicar e avaliar um modelo de intervenção cognitivo-comportamental para meninos vítimas de Violência Sexual (VS). Especificamente em relação à VS contra crianças e adolescentes destaca-se a importância de se investigar sua ocorrência e alternativas de tratamento para vítimas masculinas, tendo em vista a escassez de estudos sobre essa temática (HOHENDORFF et al., 2014).

O transtorno de estresse pós-traumático (TEPT) que é dos transtornos mais comuns entre as vítimas, principalmente do sexo masculino. Distúrbio esse caracterizado com a dificuldade do indivíduo conviver com algo assustador, podendo durar por anos essa lembrança de relembrar situações traumáticas, onde na maioria das vezes não basta somente tratamento em psicoterapia, é necessário tratamento medicamentoso (HOHENDORFF et al., 2014).

No artigo 3, foi realizada uma pesquisa no centro de referência especializado no Vale do Itajaí, onde constatou-se a descrição de uma rotina desafiadora do psicoterapeuta e suas dificuldades no seu trabalho no CREAS, devido a falta de estrutura, recursos para atendimentos, falta de aperfeiçoamento por parte dos profissionais na área, o que torna o tratamento dessas crianças e adolescentes tardios em relação ao seu desenvolvimento após o trauma (CAMPOS; SANTOS; PORTES, 2019).

Nos estudos 4 e 5, os resultados apontaram que a Terapia Cognitiva Comportamental empregada para as crianças e adolescentes vítimas de abuso sexual, utilizada através de grupo terapia ou em atendimentos individuais, demonstram bons resultados quanto à redução dos sintomas de depressão e ansiedade, bem como na reestruturação de crenças e comportamentos disfuncionais, além da prevenção à revitimização (PETTER; MAZONI, 2016; SILVA; CALOU; MACÊDO, 2019).

Apesar dessas características específicas, as crianças e adolescentes vítimas de abuso sexual apresentam transtornos em consequência como alterações cognitivas, emocionais, comportamentais e agressividade. Na maioria das vezes, elas possuem comportamentos autodestrutivos, tentando suicídio e automutilação.

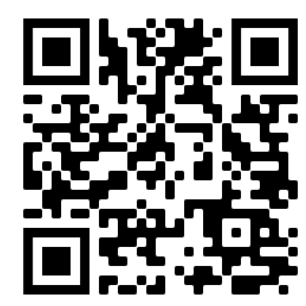

http://www.revistaphd.periodikos.com.br V. 01, No 07, dezembro de 2021 DOI: 10.53497/phdsr1n7-001 Todos os direitos reservados@ 


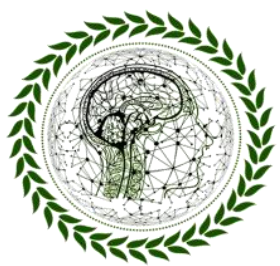

PhD Scientific Review

ISSN 2676 - 0444

No artigo 6, observou-se a realização de um estudo de caso, onde foi analisado de modo particular referente ao abuso sexual infanto-juvenil em que houve melhorias com a Terapia Cognitivo Comportamental substanciais referente às cognições, comportamentos e sentimentos da paciente adolescente, com expressivo aumento na qualidade de interações sociais e diminuição do sentimento de culpa, ansiedade e medo (GONÇALVES; SILVA, 2018).

Outro aspecto diz respeito a importância da qualificação do psicólogo no artigo de número 7, que reforça o quanto é necessário a qualificação do profissional terapêutico para ter êxito no acompanhamento psicoterápico e escuta especializada nas entrevistas forenses onde possa colher informações sobre o abusador e saber como acompanhar à criança infanto-juvenil de acordo com suas dores e medos que cada indivíduo sente em particular (AZNAR-BLEFARI et al., 2020).

No artigo de número 8, tendo em vista o impacto da vitimização pelo abuso sexual em milhares de crianças e adolescentes no Brasil e no mundo, e o importante papel que a Psicologia pode exercer nos diferentes contextos em que atua, ressalta-se a importância da realização de estudos que investiguem quem são os psicólogos que trabalham com esse fenômeno, como atuam, que instrumentos utilizam, entre outros aspectos. A avaliação psicológica em situações de abuso sexual tem sido cada vez mais valorizada por setores como a Justiça, e demandas como essa se apresentam no dia-a-dia de psicólogos em diferentes áreas de trabalho (PELISOLI; DELL'AGLIO, 2015).

O estudo do artigo 9 cita dois casos clínicos referentes as meninas participantes ( 9 e 16 anos) que foram vítimas de VS intrafamiliar, em que buscou-se adaptar e avaliar o programa de psicoterapia cognitivo-comportamental no atendimento individual de meninas vítimas de violência sexual, uma vez que nem sempre a demanda de casos é suficiente para a formação de grupos e os locais podem não apresentar estrutura física adequada para atendimentos grupais (SCHNEIDER; HABIGZANG, 2016).

Segundo os autores do artigo 9, a aplicação do modelo Superar tiveram um impacto positivo tanto no tratamento individual como no grupal. A avaliação apresentou os resultados dos instrumentos psicológicos que avaliaram sintomas de depressão, estresse e TEPT aplicados 


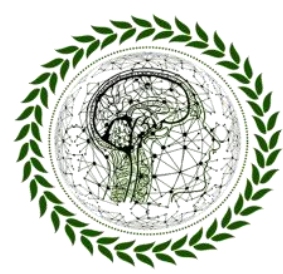

PhD Scientific Review

ISSN 2676 - 0444

antes e depois do tratamento (SCHNEIDER; HABIGZANG, 2016).

Quanto às técnicas aplicadas, observou-se a maior utilização das seguintes técnicas: Associação livre, técnicas lúdicas (artigos 1, 2, 3 e 8), a psicoeducação (artigos 1, 4, 5 e 9), a prevenção da recaída (artigos 4, 5, 6 e 9), o treino de inoculação do estresse (artigos 4, 5 e 9), a reestruturação cognitiva (artigos 2 e 4) e o relaxamento muscular e de respiração (artigos 4, 6, 5 e 9), seguidas de: identificação de crenças e pensamentos automáticos (artigo 4), Diagrama de Conceituação Cognitiva (artigo 4), o treino de assertividade (artigo 4), a reestruturação da memória traumática (artigo 4), a resolução de problemas (artigo 4), o ensaio comportamental (artigo 4), a exposição e prevenção de respostas (artigo 4), role-play com um boneco (artigo 4), a dessensibilização (artigo 4), Escuta Especializada (EF) (artigo 7), Depoimento Especial (DE) (artigo 7), Perícia Psicológica (artigo 7) e rapport (artigo 7), Entrevista cognitiva (artigo 8), Avaliação da Validade da Declaração - Statement Validity Assessment - SVA (artigo 8), Família terapêutica (artigo 8); Instrumentos de Avaliação: Entrevista semi-estruturada (artigo 9), Escala de Estresse Infantil (ESI) (artigo 9), Inventário de Depressão Infantil (CDI) (artigo 9) e Entrevista estruturada com base no DSM IV/ SCID (artigo 9).

A técnica psicoeducação (artigos 1, 4, 5 e 9), é direcionada para aprendizagens específicas que têm por objetivo ensinar aos pacientes a verificação e monitorização dos pensamentos automáticos, aprender acerca das relações entre cognição, afeto e comportamento, e substituir pensamentos distorcidos por outros mais realistas, além de testar a validade de pensamentos automáticos e crenças nucleares (KNAPP; BECK, 2008).

O Treinamento de Inoculação Estresse (TIE) - (artigos 4, 5 e 9) foi desenvolvido em 1974 por Meichenbaum. Inicia-se com um mapeamento do problema, da gravidade, do impacto e da frequência da resposta. Com isso, o paciente poderá compreender a origem do medo e da ansiedade, possibilitando um domínio de seus medos, trabalhando-se a ressignificação da memória traumática. Após, é realizado um treinamento de habilidades de manejo e enfrentamento com foco na solução de problema, em que são utilizados conceitos acerca de habilidades e modo de funcionamento, com demonstrações e ensaios inicialmente no consultório do psicólogo. 


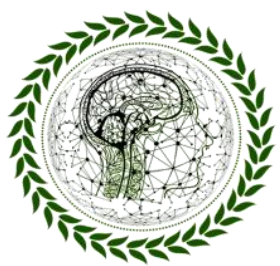

PhD Scientific Review

ISSN 2676 - 0444

No artigo 9, as participantes construíram seu "Botão de emergência", que visava ser acionado para lidar com lembranças intrusivas sobre o AS. Após os ensaios no consultório, o paciente utiliza externamente em situações problemáticas, mas não diretamente focadas nos comportamentos visados. Ao final, é feita uma revisão para verificação e avaliação da autoeficácia, aplicando-as numa escala do menor até o mais difícil problema de enfrentar (KNAPP; CAMINHA, 2003).

Os pais e responsáveis pela criança precisam de orientação mais abrangente em relação ao assunto após a descoberta da violência sexual com seu filho(a) e como lidar com a convivência no cotidiano. A intervenção psicológica especializada é muito importante para romper esse ciclo de violência sexual e traumas futuros, fazendo com que a criança e o adolescente tenham uma perspectiva e saiba lidar com a situação no decorrer de sua vida.

\section{CONSIDERAÇÕES FINAIS}

Para as considerações finais do presente artigo, os objetivos foram alcançados na questão de mostrar as técnicas utilizadas pelos psicólogos em atendimentos de crianças e adolescentes que sofreram abuso sexual.

No que diz respeito a bibliografia sobre o abuso sexual na infância e adolescência, permitiu um melhor entendimento da importância desse tema, pois existem diferentes formas que o abuso pode ser classificado baseado em suas variadas categorias de abusadores. Trazer esse conhecimento poderá proporcionar uma melhor intervenção e assim melhorar a atuação do psicólogo em casos como estes apresentados.

Em relação à abordagem terapêutica, destacou-se a terapia cognitiva comportamental por apresentar evidências científicas, sendo capaz de melhorar a vida da vítima, podendo reestruturar suas crenças e comportamentos disfuncionais e tendo a possibilidade de ensinar ao paciente como ele pode utilizar essas técnicas no seu dia-a-dia, conseguindo prevenir uma possível recaída, sendo possível ser de forma individual ou grupo terapia. Ao que concerne as técnicas, foi demostrando que a TCC possui diversas técnicas que podem ser adotadas para crianças ou 


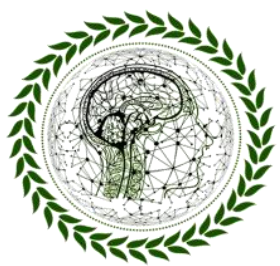

PhD Scientific Review

ISSN 2676 - 1444

adolescentes.

Outro ponto importante é a vasta quantidade de transtornos que pode ser ocasionado pelo abuso sexual na infância e adolescência. O transtorno de estresse pós-traumático (TEPT) foi o mais encontrado na literatura. Mas, o psicólogo munido de conhecimentos a cerca de outros casos consegue melhorar sua atuação, tendo em vista o bem-estar de seu paciente.

Finalizando, a pesquisa permitiu mostrar casos já encontrados na literatura, os transtornos mais comuns e como a terapia cognitiva comportamental (TCC) pode se mostrar eficaz, abrindo espaço para que as técnicas sejam melhores utilizadas pelos psicólogos, proporcionando uma melhor intervenção e tratamento.

\section{REFERÊNCIAS}

AUGUSTO, H. S. et al. Atuação do psicólogo em casos de abuso sexual infantil. Revista eletrônica de trabalhos acadêmicos - Universo/Goiânia, ano 2, n. 3, 2017.

AZEVEDO, E. C. Atendimento psicanalítico a crianças e adolescentes vítimas de abuso sexual. Psicol. cienc. prof., Brasília , v. 21, n. 4, p. 66-77, dez. 2001.

AZNAR-BLEFARI, C et al. Atuação de Psicólogos em Alegações de Violência Sexual: Boas Práticas nas Entrevistas de Crianças e Adolescentes. Psico-USF, Bragança Paulista, v. 25, n. 4, p. 625-635, out./dez, 2020.

BRASIL. Lei no $\mathbf{9 . 6 1 0}$, de 19 de Fevereiro de 1998. Altera, atualiza e consolida a legislação autorais e dá outras providências. Brasília: DF, Presidência da República, 1998.

BRASIL. Ministério da Saúde (MS). Boletim epidemiológico. Brasilia: MS, 2018.

BRASIL. Ministério dos direitos humanos. Balanço das denúncias de violação de direitos humano. Brasília: Ministério dos direitos humanos, 2016.

CAMPOS, B. C. S.; SANTOS, I. L.; PORTES, J. A atuação do psicólogo no CREAS com crianças e adolescentes vítimas de abuso sexual no vale do Itajaí/SC. Revista Psicologia em Foco Frederico Westphalen, v.11, n.16 p. 2-18, nov, 2019.

ERCOLE, F.F.; MELO, L.S.; ALCOFORADO, C. L.G. C. Integrative review versus systematic review. Reme Rev Min Enferm, 2014.

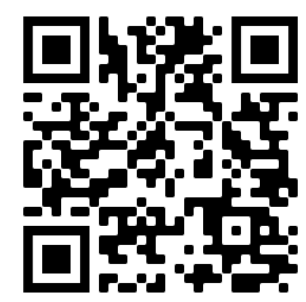

http://www.revistaphd.periodikos.com.br V. 01, No 07 , dezembro de 2021 DOI: 10.53497/phdsr1n7-001 


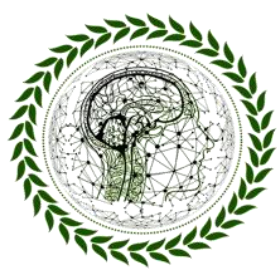

PhD Scientific Review

ISSN 2676 - 1444

GONÇALVES, J.; SILVA, J. V.Terapia Cognitivo-Comportamental em situação de Abuso Sexual: um Estudo de Caso. Revista Psicologia, Diversidade e Saúde, v., n.3, p.423- 432, 2018.

HABIGZANG, L. F. et al . Avaliação de um modelo de intervenção psicológica para meninas vítimas de abuso sexual. Psic. Teor. e Pesq., Brasília , v. 24, n. 1, p. 67-75, mar. 2008 .

HOHENDORFF, J. V. Adaptação e Avaliação de uma Intervenção CognitivoComportamental para Meninos Vítimas de Violência Sexual. Avaliação Psicológica, Psicol. Reflex. Crit., v.27, n.3, 2014.

KNAPP, P.; BECK, A. T. Fundamentos, modelos conceituais, aplicações e pesquisada Terapia Cognitiva. Revista Brasileira de Psiquiatria, p. 54-64, 2008.

KNAPP, P.; CAMINHA, R. M. Terapia cognitiva do transtorno de estresse póstraumático. Revista Brasileira de Psiquiatria, p. 31-36, 2003.

MAFFINI G.; CASSEL, P. A. Intervenções da Terapia Cognitivo-Comportamental (TCC) para transtorno de estresse pós-traumático: estudo de caso. Revista Sociais \& Humanas, v.34, n.1, 2021.

PELISOLI, C. L.; DELL'AGLIO, D. D. Práticas de profissionais de Psicologia em situações de abuso sexual. Arquivos Brasileiros de Psicologia, Rio de Janeiro, v.67, n.1, p.51-67, 2015.

PETTER, L. M.; MAZON, C. M. Resultados da terapia cognitiva comportamental em crianças e adolescentes vítimas de abuso sexual: revisão integrativa da literatura nacional. Revista Ampliar, v.3, n.3, 2017.

SCHNEIDER, J A.; HABIGZANG, L. F. Aplicação do Programa Cognitivo-Comportamental Superar para atendimento individual de meninas vítimas de violência sexual: estudos de caso. Avances en Psicología Latinoamericana, v. 34, n. 3, p. 543-556 Universidad del Rosario Bogotá, Colombia, 2016.

SILVA, K.A.; CALOU, A. F. F.; MACÊDO F. R. M. M. Abuso sexual infanto-juvenil em uma análise sobre técnicas em terapias cognitivo-comportamentais em grupo (TCCG) Periódico do Núcleo de Estudos e Pesquisas sobre Gênero e Direito Centro de Ciências Jurídicas - Universidade Federal da Paraíba, v.8, n.5, 2019.

SOARES, E. M. R. et al. Perfil da violência sexual contra crianças e adolescentes. R.Interd., v.9, n.1, 2016.

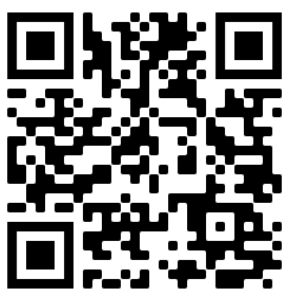

http://www.revistaphd.periodikos.com.br

V. 01, No 07, dezembro de 2021

DOI: 10.53497/phdsr1n7-001

Todos os direitos reservados@ 